ASLI QoL 2021

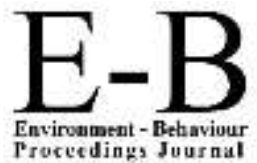

\title{
AQoL2021LangkawiIsland
}

https://www.amerabra.org; https://fspu.uitm.edu.my/cebs; https://www.emasemasresources.com/ $5^{\text {th }}$ ABRA International Conference on Quality of Life Holiday Villa Langkawi, Langkawi Island, Malaysia, 15-16 Dec 2021

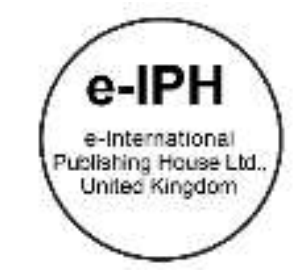

\section{Investigating the Impact of Saudi QoL Program on Neighbourhoods' Public Spaces: Case of Riyadh Neighbourhoods}

\author{
Lobna A. Mostafa \\ Architectural Engineering Dep. Dar Al Uloom University, Riyadh, Kingdom of Saudi Arabia. \\ Architecture Dep. College of Fine Arts, Menia University, Egypt \\ Lobna.m@dau.edu.sa, arch.lobna@gmail.com \\ Tel : +966569691849
}

\begin{abstract}
"Humanization of Neighborhoods Initiative" was launched in 2020, under the QoL program aiming at improving and adapting public spaces in the city of Riyadh into pedestrian-friendly ones and fewer cars' dependent which can help accomplish the Saudi Vision 2030.

This research aims at investigating the reflections of the QoL program on the urban and social life in Riyadh neighborhoods focusing on the streets to promote social activities and walkability into a prime physical activity in neighborhoods.

The research follows mixed methods; a qualitative approach is in the literature review and quantitative analysis in the research survey. It provides recommendations for city planners for developing pedestrian infrastructure.
\end{abstract}

Keywords: Saudi Vision 2030, Quality of Life, QoL, Public Space, walkability, community design, Placemaking

eISSN: 2398-4287@ 2021. The Authors. Published for AMER ABRA CE-Bs by e-International Publishing House, Ltd., UK. This is an open access article under the CC BYNC-ND license (http://creativecommons.org/licenses/by-nc-nd/4.0). Peer-review under responsibility of AMER (Association of Malaysian Environment-Behaviour Researchers), ABRA (Association of Behavioural Researchers on Asians/Africans/Arabians) and CE-Bs (Centre for Environment-Behaviour Studies), Faculty of Architecture, Planning \& Surveying, Universiti Teknologi MARA, Malaysia.

DOI: https://doi.org/10.21834/ebpj.v6i18.3024

\subsection{Introduction}

With the increasing pace of urbanization and population growth in big cities, many problems affected the environment, and people's lifestyles appeared. Where Roads and streets overwhelmed the other alternative transportation, neighborhoods became oriented towards providing housing to accommodate demand. While growing, many neighborhoods became poor of humanization. Rapid developments in cities led to the absence of a human dimension in residential neighborhoods and a lack of interest in forming the built environment. They were associated with increased vehicle usage rates at the expense of the pedestrian-friendly environment, which ultimately led to urban environments that do not meet human needs. The quality of life, QOL, in a city begins with a relationship between human beings and the surrounding environment, reflecting on his lifestyle and behavior. The focus on physical activity is explained by how inactivity today accounts for an increasing proportion of deaths and disability worldwide and is associated with high health care costs and productivity losses (Lee Im. et al., 2012). The relationship between physical activity levels and the physical environment in cities has been subject to many different studies. However, studies often focus on specific subsections of cities or key aspects of the built environment that might influence activity levels, such as parks, cycle paths, and public transportation systems (Sallis JF et al. 2016). In these studies, the built environment has consistently been shown to affect physical activity among the population; thus, there is much scope to use the city's setting to increase physical activity opportunities. In light of this, WHO and other bodies have recommended that

eISSN: 2398-4287C 2021. The Authors. Published for AMER ABRA cE-Bs by e-International Publishing House, Ltd., UK. This is an open access article under the CC BYNC-ND license (http://creativecommons.org/licenses/by-nc-nd/4.0/). Peer-review under responsibility of AMER (Association of Malaysian Environment-Behaviour Researchers), ABRA (Association of Behavioural Researchers on Asians/Africans/Arabians) and cE-Bs (Centre for Environment-Behaviour Studies), Faculty of Architecture, Planning \& Surveying, Universiti Teknologi MARA, Malaysia.

DOI: https://doi.org/10.21834/ebpj.v6i18.3024 
the discipline of urban Planning consider the population's needs in terms of physical activity. This relation has been strongly reflected in the well-defined concept of a "healthy city" (WHO, 2016).

Therefore, Saudi Vision 2030 focused on improving the quality of urban life through the QoL program launched in 2020 to enhance Livability in Saudi cities. This paper investigates the role of planning and design urbanism in shaping neighborhoods' urban environment within the framework of humanizing cities and QoL in line with Saudi vision 2030.

\section{Nomenclature}

PS public spaces

QoL Quality of life

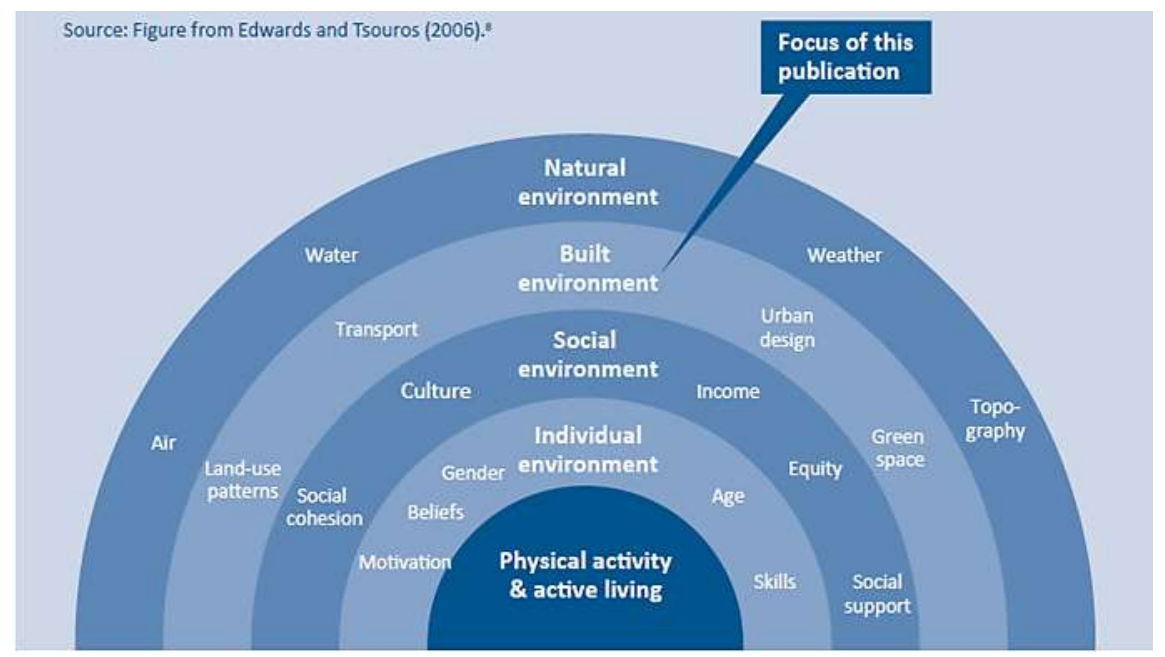

Fig.1: Factors influencing physical activity in communities

(Source: Breda 2018)

\subsection{Objectives}

Two concepts are central to this research: built environment elements related to QoL, mainly outdoor public spaces, and physical activity as a part of everyday life for residents of neighborhoods. Accordingly, this paper provides insights on the importance of the social-urban dimensions of sustainable public spaces based on visits to one of Riyadh's neighborhoods, the Al-Falah district, and a survey of its residents in 2021.

The following underlying objectives guided the research:

- Identifying how the city of Riyadh adopted the "Humanization of Neighborhoods Initiative" from a broad framework into applied methods in the redesign of public spaces in Al-Falah.

- Evaluating the impact of the public spaces upgrading project on the daily life and activities of the residents and their QoL.

- Exploring the resident's tendency to participate in placemaking activities, if any.

\subsection{Structure}

The paper first discusses essential literature in QoL in neighborhoods, shading light on the QoL Program in Saudi Arabia and its BuiltEnvironment related initiative "Humanization of Neighborhoods Initiative." The second part is a description of the development project of Al-Falah into a more sustainable-walkable neighborhood; it includes both the initial status and the development phases of the neighborhood.

The third part introduces the methodology of this study, particularly the survey instrument, data collection process, and applied statistical analysis. The analysis of the survey data is presented and discussed in section four with a focus on the motivational factors that prompted today's residents of Al-Falah to walk more, be active more, and engage in more outdoor social activities, their evaluation for the elements of public spaces and their level of satisfaction of the development project taking place in their neighborhood, and their perceived social interactions and level of community engagement.

\subsection{Literature Review}

\subsection{Quality of Life, QoL}

QoL is a broad and complex concept that measures satisfaction in the "most valued" aspects of a citizen's life. One of the oldest yet comprehensive definitions is by WHOQOL Group, 1995, that QoL "An individuals' perceptions of their position in life in the context of the culture and value systems in which they live, and in relation to their goals, expectations, standards, and concerns. It is a broad- 
ranging concept that is affected in a complex way by the persons' physical health, psychological state, level of independence, social relationships, and their relationship to salient features of their environment". While (Hashem 2017) concluded that the comprehensive concept of QoL focuses on creating the principle of integration between the development of the place and the building of human who enjoys the material and moral components of life. However, this definition can be highly subjective. Thus, there was a need for tangible values for qualitative perceptions to establish an objective assessment of the quality of living for transfers to over 460 cities worldwide. Carefully selected factors representing the criteria considered most relevant to international executives (mercer.2014).

According to systematic review and meta-analysis of studies walking and cycling reduce all-cause mortality. Public health approaches would have the most significant impact if they increased walking and cycling levels in groups that currently show the lowest levels of these activities (Kelly P, 2014). For decades, urban Planning was dominated and driven by a strong focus on cars, but this is now changing to creating cities for people with balanced mobility systems and encouraging active mobility (Arup, 2016). A central concern for many cities today is to plan to improve people's QoL and create urban environments that are responsive to the everyday lives of their citizens (WHO, 2016).

\subsection{International QoL Indicators}

Many international QoL ranking indexes conduct city-to-city comparisons that summarize the difference in the quality of living between any two cities. Each Quality of Living index has its parameters to measure the QoL of the city and assess a detailed breakdown of the category scores that form the resulting index, after which a score report summarizes the differences for each of the measured factors. Although Quality of Living indexes varied in many ways, however, we could identify standard parameters based on the following categories: Economic environment, Housing \& built environment, public services, infrastructure and transport, Recreation, Natural environment, Medical and health considerations, Consumer goods, Political and social environment, Schools and education, and Sociocultural environment.

Following are six of the most comprehensive and internationally recognized global indexes defining and measuring QoL from different angles. These indexes are (based on VRP,2018):

1. The Global Livability Ranking produced by Economist Intelligence Unit (EIU) ranks 140 cities for their urban quality of life based on stability, healthcare, culture and environment, education, sports, and infrastructure assessments.

2. The Mercer Quality of Living Survey ranks 231 cities based on the following dimensions: transportation, political and socio-cultural environment, public service, health, economic environment, schools and education, natural environment, housing, theatres and cinemas, sports, consumer goods, and restaurants and leisure.

3. The Annual Lifestyle List, which conducted by Monocle Magazine's, lists the top 25 most liveable cities based on the following criteria: international connectivity, environmental issues, access to nature, architectural quality, urban design, medical care, business conditions, safety crime, culture, restaurants, tolerance, and proactive policy developments.

4. The World Happiness Index 2017 ranks 155 countries based on happiness levels explained with the following dimensions: corruption, freedom of choice, life expectancy, GDP per capita, freedom of choice, social support, and generosity.

5. The OECD Better Life Index, which compares well-being across countries, is based on 11 identified essential topics: safety, health, income, jobs and work-life balance, education and life satisfaction, housing, environment, community, and civic engagement.

6. The ARRP Livability Index is a signature initiative of the Public Policy Institute to measure the quality of life in American communities across multiple dimensions: transportation, health, economy and education, housing neighborhood, environment, engagement, and equal opportunities.

Based on the analytical overview matrix of QoL global indices shown in (Table 1.) it's clear that housing environments and neighborhoods are amongst the most common domains in the six analyzed QoL indices. They are the main measured QoL parameters in this research.

\subsection{Quality of Life Program in Saudi Arabia}

In 2016 The Saudi Council of Economic Affairs and Development defined 12 Vision Realization Programs (VRP) of strategic importance for the government of Saudi Arabia to achieve the objectives established in Vision 2030. Among which is the QoL Program, launched in 2018. This program mainly focuses on making Saudi Arabia a top living destination for citizens and residents. This program focuses on two aspects:

- Improving individuals' lifestyle: Developing an ecosystem to support and create new options that boost participation in cultural, entertainment, and sports activities.

- Enhancing QoL: Developing suitable activities that contribute to enhancing the QoL of individuals and families, creating jobs, diversifying economic activity, and boosting the status of SA cities so that they rank among the best cities in the world. Consequently, the VRP identified "Quality of Life" as the central underlying concept of the program (QoL,2018).

One of the critical approaches under the QoL program is Housing, Urban Design, and Environment, those focuses on providing housing for people of all ages, incomes, and abilities and allowing everyone to live in a quality neighborhood. Additionally, it focuses on upgrading the urban design and environmental context to enable residents to have higher access to daily services and job opportunities. It also fosters healthy habits like a more active physical life (such as walking). The KSA underperforms on access to nature, affordable housing, urban design, and quality of the environment, all of which are important for the everyday lived experience of residents. For example, on an independent measure of walkability ("Walk score"), Riyadh is half as walkable as New York, Singapore, and London. The KSA lags benchmarks in multiple dimensions. One significant lag is the average steps per person per day, where KSA lags best 
practices by more than 1000 steps per day $(3,800)$. Riyadh is tenth of WHO standards regarding available green space per capita (VRP, 2018).

Table 1. Overview matrix of quality-of-life global indices and their main domains

\begin{tabular}{|c|c|c|c|c|c|c|c|c|c|c|}
\hline \multirow[b]{2}{*}{ Index } & \multicolumn{5}{|c|}{ Livability } & \multicolumn{5}{|c|}{ Lifestyle } \\
\hline & $\begin{array}{c}\text { Infrastructure } \\
\text { \& } \\
\text { Transportatic } \\
n\end{array}$ & $\begin{array}{l}\text { Housing, } \\
\text { Urban } \\
\text { Design \& } \\
\text { Environment }\end{array}$ & $\begin{array}{l}\text { Healthca } \\
\text { re }\end{array}$ & $\begin{array}{l}\text { Economic \& } \\
\text { Education } \\
\text { Opportunity }\end{array}$ & $\begin{array}{c}\text { Security \& } \\
\text { socio- } \\
\text { environment }\end{array}$ & Sports & $\begin{array}{l}\text { Heritage, } \\
\text { Culture } \\
\text { \&Arts }\end{array}$ & Entertainment & t $\begin{array}{c}\text { Recreatio } \\
n\end{array}$ & $\begin{array}{c}\text { Social } \\
\text { Engagement }\end{array}$ \\
\hline $\begin{array}{c}\text { ElU } \\
\text { Liveability } \\
\text { Ranking }\end{array}$ & $\begin{array}{c}\text { Infrastructu } \\
\text { re }\end{array}$ & Environmen & $\begin{array}{l}\text { Healthca } \\
\text { re }\end{array}$ & Education & Stability & $\begin{array}{c}\text { Sporting } \\
\text { availability }\end{array}$ & $\begin{array}{l}\text { Culture } \\
\text { availability }\end{array}$ & & $\begin{array}{l}\text { F\&B and } \\
\text { Consumer } \\
\text { goods }\end{array}$ & \\
\hline $\begin{array}{l}\text { Mercer } \\
\text { Quality of } \\
\text { Living } \\
\text { Index }\end{array}$ & Transportation & $\begin{array}{c}\text { Natural } \\
\text { Environmen } \\
\mathrm{t} \\
\text { Housing }\end{array}$ & Health & $\begin{array}{l}\text { Economic } \\
\text { Environme }\end{array}$ & $\begin{array}{c}\text { Securitv } \\
\text { \&Socio- } \\
\text { environme } \\
\text { nt. }\end{array}$ & Sports & $\begin{array}{c}\text { Media } \\
\text { Availability }\end{array}$ & $\begin{array}{c}\text { Consumer } \\
\text { Goods }\end{array}$ & ransportation & \\
\hline $\begin{array}{c}\text { Monocle } \\
\text { QoL }\end{array}$ & $\begin{array}{c}\text { Int'l } \\
\text { Connectivi } \\
\text { ty } \\
\text { Public } \\
\text { Transport }\end{array}$ & $\begin{array}{c}\text { Environmen } \\
\text { t \& Nature } \\
\text { Arch. } \\
\text { \&quality } \\
\text { desiguan } \\
\text { design }\end{array}$ & $\begin{array}{l}\text { Medical } \\
\text { Care }\end{array}$ & $\begin{array}{l}\text { Business } \\
\text { Conditions }\end{array}$ & $\begin{array}{l}\text { Safetyl } \\
\text { Crime }\end{array}$ & & culture & $\begin{array}{l}\text { Restauran } \\
\text { ts }\end{array}$ & $\begin{array}{c}\text { Tolerance } \\
\text { Proactive } \\
\text { Policy }\end{array}$ & \\
\hline $\begin{array}{l}\text { World } \\
\text { Happiness } \\
\text { Report }\end{array}$ & & & $\begin{array}{l}\text { Life } \\
\text { expectan } \\
\text { cy }\end{array}$ & $\begin{array}{l}\text { GDP per } \\
\text { capita }\end{array}$ & $\begin{array}{l}\text { Corruption } \\
\text { Freedom } \\
\text { of choice }\end{array}$ & & & & & $\begin{array}{c}\text { Social } \\
\text { support } \\
\text { Generosit } \\
\text { y }\end{array}$ \\
\hline $\begin{array}{l}\text { OECD } \\
\text { Better Life } \\
\text { Index }\end{array}$ & & $\begin{array}{c}\text { Housing } \\
\text { Environmen } \\
t\end{array}$ & Health & $\begin{array}{c}\text { income, } \\
\text { jobs \& a- } \\
\text { life } \\
\text { balance } \\
\text { Education } \\
\& \\
\text { satisfactio } \\
n\end{array}$ & Safety & & & & & communit \\
\hline $\begin{array}{l}\text { AARP } \\
\text { Livability } \\
\text { Index }\end{array}$ & $\begin{array}{l}\text { Transport } \\
\text { ation }\end{array}$ & $\begin{array}{l}\text { Housing \& } \\
\text { Neiahborhoo } \\
\mathrm{d} \\
\frac{\text { Environmen }}{\mathrm{t}}\end{array}$ & Health & $\begin{array}{c}\text { Opportunit } \\
y\end{array}$ & & $S$ & al Engagem & ent & & $\begin{array}{l}\text { Civic } \\
\text { Engagem } \\
\text { ent }\end{array}$ \\
\hline
\end{tabular}

(Source: Based on the Vision 2030 VRP QoL Program, 2018)

Note: Framed factors are the ones related to QoL in neighborhoods as a focus of this study

\subsection{Humanizing Neighbourhoods Initiative}

"Humanizing Neighbourhoods Initiative" was launched in 2020 by the Saudi Ministry of Housing as part of the "Enhancing QoL in neighborhoods" program feeding back in the National Urban Strategy. The main goals of this initiative are raising the QoL in the city of Riyadh till reaching the boundaries of the land plots in the residential neighborhoods, contributing to the humanization of cities in the KSA and the city of Riyadh in particular, maximizing the economic and social benefit from Riyadh Megaprojects, Improving the urban visual image and urban design, and enhancing the level of safety in the neighborhood streets $(\mathrm{MOH}, 2020)$.

This program is one of the fundamental pillars in the "Humanizing The Cities" national program and makes them more suitable for humans by applying the standards of sustainability and comprehensive accessibility standards and raising the levels of safety and security in an urban context that achieve both functions and beauty. It also promotes traffic safety and hygiene systems. It organizes PS by linking the pedestrian network to public utilities and public stations and allocating parking spaces for vehicles, bicycle paths, and walking movement streets. The initiative methodology is based on the essential requirements for placemaking, environment, and urban characteristics of residential neighborhoods in general (MOH, 2020).

\subsection{Public Spaces in Neighbourhoods}

Public spaces in the cities are the drivers for sustainable change and social cohesion. Streets usually account for $80 \%$ of public spaces, and parks and gardens are $20 \%$. Thus pedestrians are legitimate road users, yet they are frequently overlooked in transportation systems. Moreover, more people walking also provides more eyes on the street, enhancing safety and reducing crime (Goodyear, 2013). 
In acknowledgment of the importance of PS to communities' welfare, UN-Habitat launched the Public Space Program in 2012 to support local governments in creating and promoting socially inclusive, integrated, connected, environmentally sustainable, and safe streets and public spaces and promoting a better QoL for all. According to World Cities Report 2020, it's intended by 2030 to provide universal access to safe, inclusive, and accessible green and public spaces, particularly for women and children, older persons, and persons with disabilities. (UN-Habitat 2020) The Global Public Space Programme set five dimensions to measure good quality public space in its Annual Report 2020. These dimensions are use and users, accessibility, amenities and furniture, comfort and safety, green environment. (UN-Habitat, P6 2022).

Al-Falah and Al-Waha districts are the two residential neighborhoods selected to apply Riyadh's "Humanizing Neighbourhoods Initiative" pilot project. Therefore, the Al-Falah district was chosen for the applied part of this study.

\section{Case Study: Upgrading The PS in Al-Falah District}

The project aims to apply sustainability standards, comprehensive accessibility, and improve safety and security in the existing urban context. Accordingly, it achieves both function and beauty and contributes to enhancing the QoL of the population; promoting traffic safety and hygiene, upgrading the conditions of urban spaces in the neighborhood and neighborhood center by linking the network of pedestrian walkways with public utilities and public transport stations and allocating parking spaces, bicycle paths, and movement in internal streets.

\subsection{Al Falah background}

Al-Falah is a residential neighborhood in Riyadh, the capital of the KSA. A square designed following the Doxiadis model with a length of $(2.0) \mathrm{km}$ and a width of $(2.0) \mathrm{km}$, approximately with a total area of $353.000 \mathrm{~m}^{2}$, it's inhabited by $(38,308)$ people. Al-Falah is located in the northern part of Riyadh's main road network system and is bordered by Prince Muhammad Bin Salman Road to the north, Airport Road to the east, the Northern Ring Road to the south, and Othman Bin Affan Road to the west. It is also close to many mega projects such as the Sports Track Project and Riyadh train stations. (Fig. 2)

The population of Al-Falah is $38,308 \mathrm{P}$ comprising $(0.81 \%)$ of the Capital population. The demographic structure of Al-Falah consists of $56 \%$ male and $46 \%$ female. The proportion of young ages in the age structure is high, $69.5 \%$ are 15 to 60 years, as it is a young society, while almost $26.5 \%$ are under 15 , and $4 \%$ are above 60 .

The existing young community needs encouraging to interact with its immediate surroundings, enhance communication with various events and activities, communicate with the Al-Falah neighborhood community, who meet in the mosque, school, garden, shops, and small groceries frequented by residents. Accordingly emphasizes the need to provide the appropriate urban public spaces to enhance these capabilities and activities.

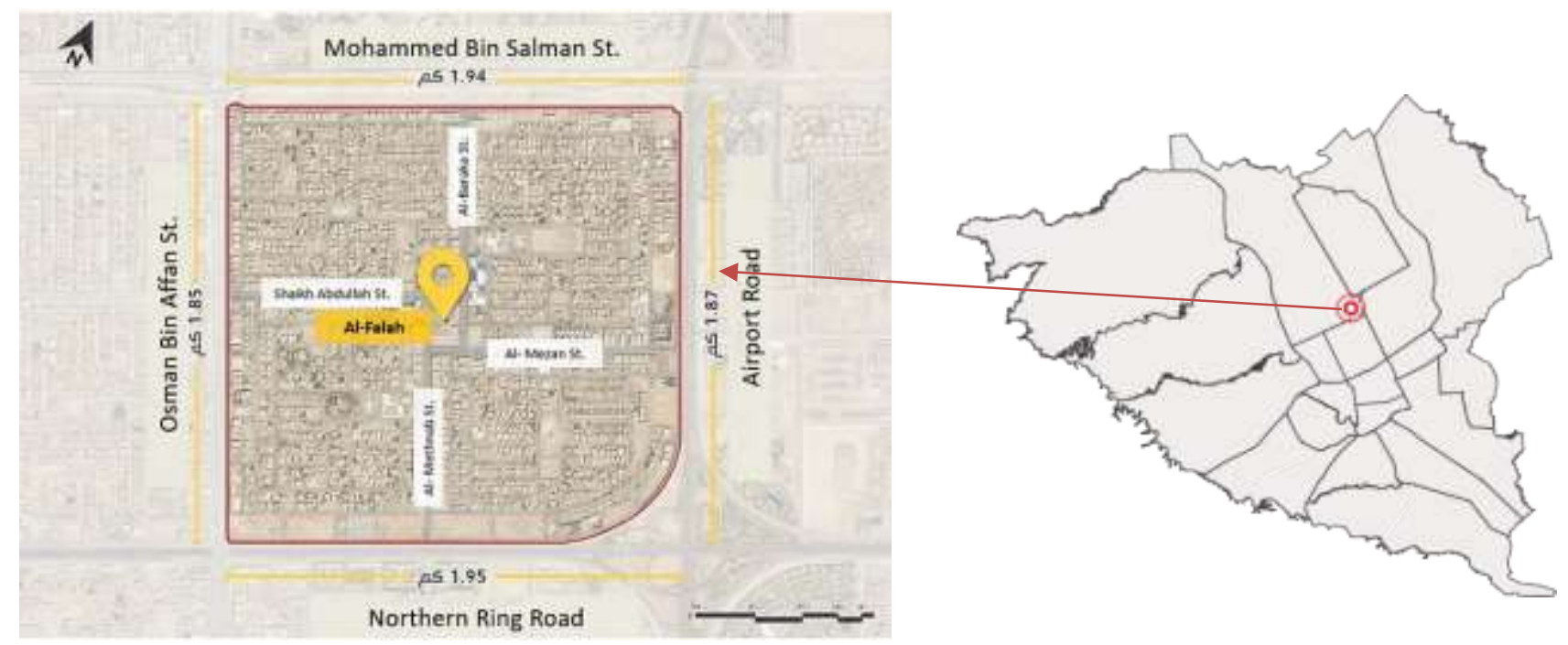

Fig. (2): Location and urban features of Al-Falah District Source: MOMRAH, Humanizing Neighbourhoods Initiative, 2020

\subsection{Initial status}

PS including streets network in Al-Falah was inappropriate: extra-wide streets with no sidewalks in most streets, absence of pedestrian's crossways and street furniture, very few signs, lack of trees and street furniture, absence of carbage containers.

Although Al-Falah is a residential neighborhood, the streets' design was oriented towards vehicles rather than community members with minimum compliance with urban streets standards-based design. (Fig. 3) 

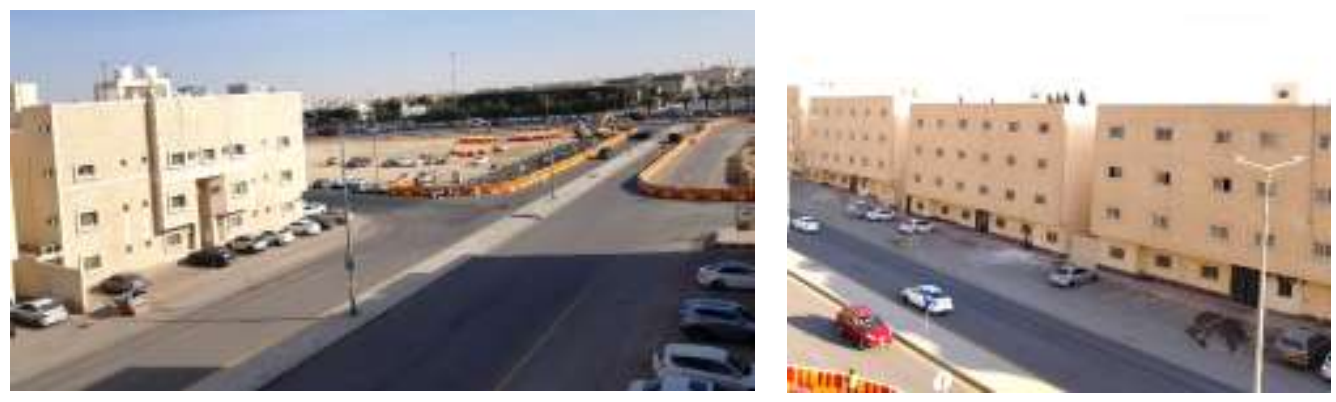

Fig. (3): Streets condition before Al-Falah Upgrading PS project (source): Author

\subsection{Project phases}

The first phase of the initiative was "Upgrading of Public Spaces in Residential neighbourhoods," which started in Al-Falah in January 2020 to upgrade the streets beginning with the four main streets of the district. However, due to the COVID19 health measurements and curfew, the completion of this phase extended beyond schedule. The redesign of the four main streets includes providing extrawide sidewalks of $12 \mathrm{~m}$, lighting poles, bollards, places prepared for trees, and car parking (Fig. 4). This phase was almost completed by September 2021. (Fig. 5) Yet, it was precise results of the shortage of needed car parking and the absence of trees and greenery.
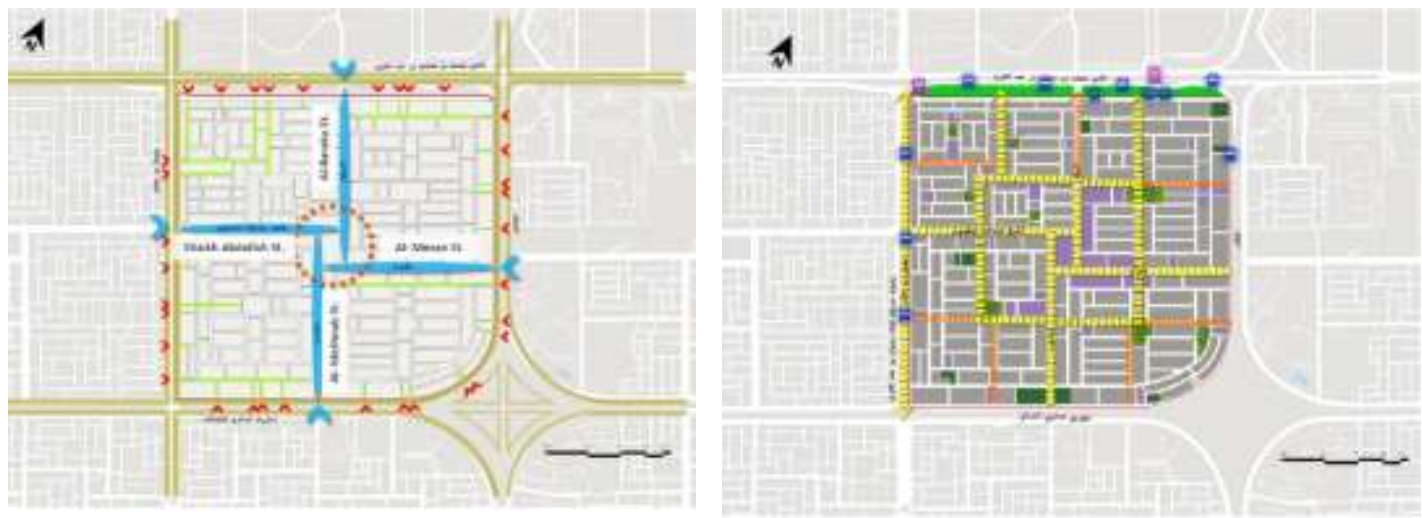

Fig. (4): Upgrading PS and Pedestrian network in Al-Falah, Phase one: main streets. (source): Al-Falah humanizing project, MOMRAH, 2020

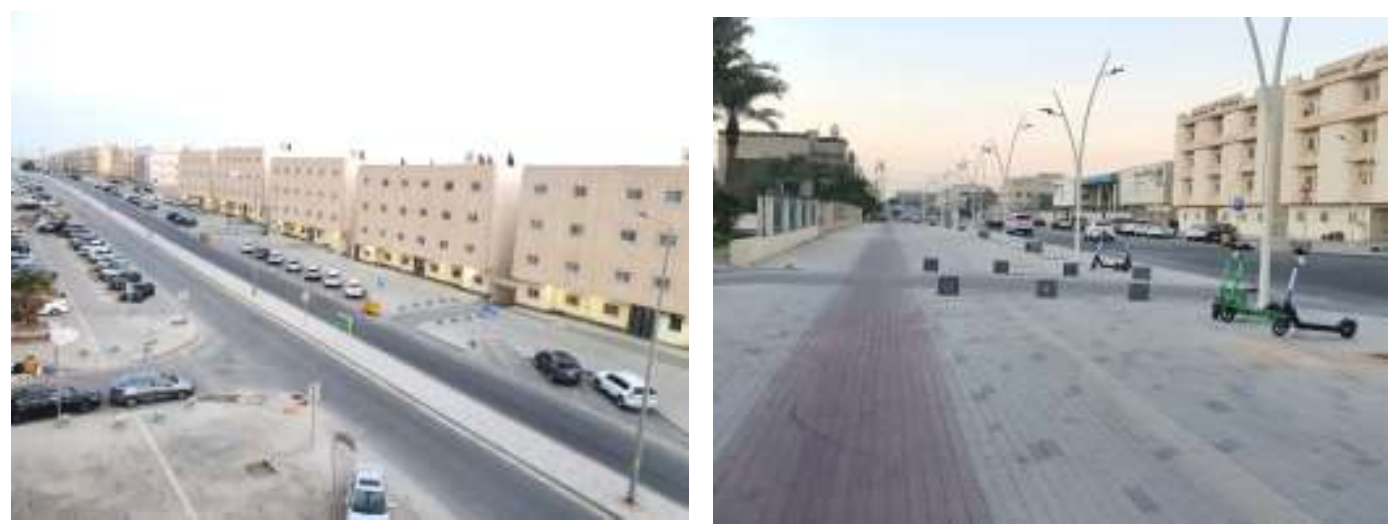

Fig. (5): Streets condition after Al-Falah Upgrading PS project

(source): Author

\subsection{Methodology}

The data presented and discussed in the following section was collected through a structured survey designed to measure the five dimensions set by the Global Public Space Programme to measure the quality of public space: use and users, accessibility, amenities and furniture, comfort and safety, green environment. The survey was conducted in Al-Falah over November 2021. This period was selected after completing the first phase of the ongoing project of Upgrading of PS. It's also one of the mildest weather in Riyadh throughout the year when people usually go out more frequently.

Participants were asked to fill out a survey instrument containing 27 mandatory questions and one open question. Seventy completed surveys were collected as a representative sample for obtaining insights and observations about the targeted population group. All 
respondents were at random, and responses were voluntary with complete anonymity. The surveys were either filled out with the collector present or distributed directly with the residents or people working in Al-Falah. While the researcher conducted the personal collecting of the questionnaire, it was ensured that participants were not influenced and that privacy rights were protected. (Table 2) shows the characteristics of the surveyed samples concerning gender, age group, period of residency, and living situation.

The research used randomization techniques in the collection of the survey data. Interviewed participants were approached on the street, around the mosque or the garden, the mosque surroundings, and asked to participate in the 10-minutes survey.

The survey structure consists of four main parts: the first part consists of 5 multiple choice questions for investigating the demographic characteristics of the participants. The second part exploring community preferences in PS in Al Falah consists of 7 multiple-choice questions. The third part Evaluates PS elements through 8 scales questions. The fourth part is the Evaluation of PS development impact on People's QoL through 7 scales questions and one optional text question.

The questions type mainly consisted of "multiple choice" and "Likert-type scaling," and answers were balanced equally. This means that the number of favorable and unfavorable answer categories are equal to prevent statistical biases. The Likert scales used in the survey instrument were 5-point scales. The answers ranged, for example, from strongly disagree to agree intensely or from not satisfied to very satisfied with a neutral answer possibility. The survey instrument was tested and reviewed by national researchers experienced in survey research and public engagement to ensure the validity of the Likert scales and other multiple-choice questions.

The total sample size of 70 participants is considered large enough to generalize results with a $95 \%$ confidence level at $\pm 4 \%$ margin of error for the neighborhood. This study applied basic statistical methods such as frequency distributions and descriptive statistics.

Scope of work and limitations: This research's main scope of work is the urban public spaces, streets in particular, in residential neighborhoods, applied in the "Al-Falah" neighborhood in the City of Riyadh, yet the suggested design guidelines could be extended to most cities of Saudi Arabia and beyond.

Table 2. Characteristics of the surveyed population.

\begin{tabular}{lccccccc}
\hline Gender & Female & Male & & & & & \\
\hline & $60 \%$ & $40 \%$ & & & & & \\
\hline Age Groups & Under $\mathbf{1 5}$ & $\mathbf{1 5 - 2 0}$ & $\mathbf{2 1 - 3 0}$ & $\mathbf{3 1 - 4 0}$ & $\mathbf{4 1 - 5 0}$ & $\mathbf{5 1 - 6 0}$ & $\mathbf{+ 6 0}$ \\
\hline Nationality & $4 \%$ & $10 \%$ & $31.4 \%$ & $24.3 \%$ & $21.4 \%$ & $6 \%$ & $2.9 \%$ \\
\hline & Saudi & Non-Saudi & & & & & \\
\hline Residents of Al-Falah & $48.6 \%$ & $51.4 \%$ & & & & & \\
\hline & Yes & No & & & & & \\
\hline Time living in Al-Falah & $67 \%$ & $33 \%$ & & & & & \\
\hline & Less a year & $\mathbf{1 - 3}$ & $\mathbf{3 - 5}$ & $\mathbf{5 - 1 0}$ & $\mathbf{1 0 - 1 5}$ & More $\mathbf{1 5}$ \\
\hline
\end{tabular}

\subsection{Findings}

\subsection{Community preferences in PS in Al-Falah}

To understand the relationship between the Al-Falah community and the PS in their district, the first dimension, "use and users', one set of survey questions (Part2) targeted exploring the community's preferences.

The survey showed that $70 \%$ of the participants go out in the neighborhood daily \& $14 \%$ weekly. Regarding companionship: $55.7 \%$ go out alone, $51 \%$ with families, $20 \%$ with friends, and $7 \%$ with other families (Fig.6). The destination for those was by order: $54.3 \%$ go to school or university, $41.4 \%$ go to work, $34.3 \%$ go out to streets, $33 \%$ to everyday needs, $25.7 \%$ to the garden, $17 \%$ to visit a friend (Fig.7).

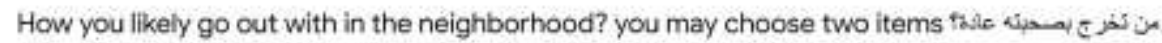
70 responses

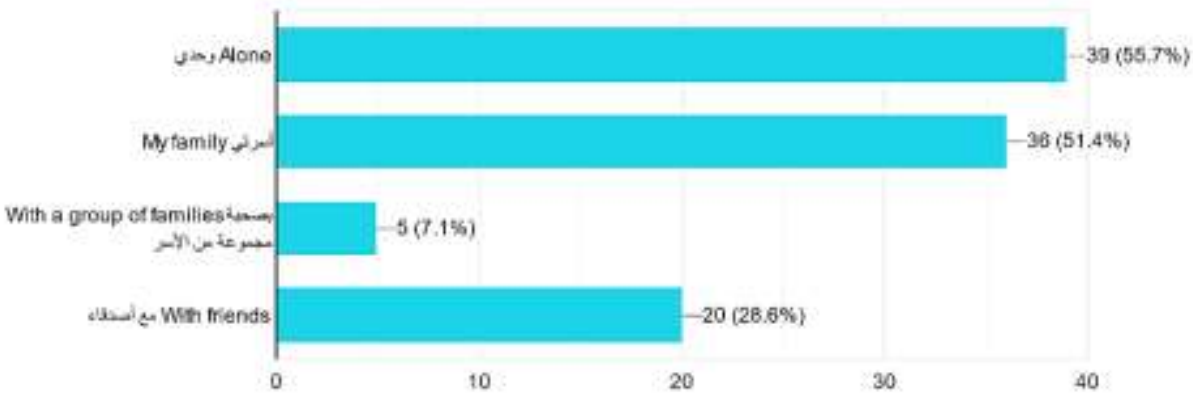

Fig. (6): usual companionship 


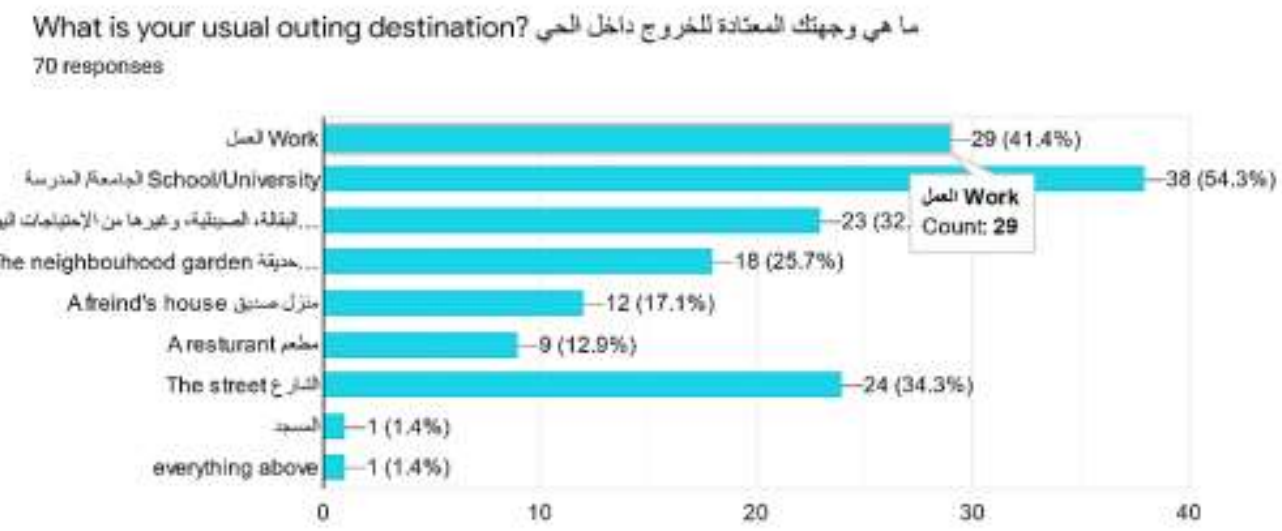

Fig. (7): regular destination in the neighborhood

The survey showed the main reason for going to PS inside Al-Falah was equally (43\%) going to work similarly to practicing walkability for fitness, followed by taking children out to play (34.3\%) and relaxation (30\%). While daily needs were the reason with $(23 \%)$, going to mosque for $(15.7 \%)$.

The most common used PS was small streets (45.3\%), main streets $65(40 \%)$, area around the mosque (31.4\%), the garden (24.3\%). One of the important indicators is the participants' dependency on walkability for their moves inside the neighborhood; almost $47 \%$ depending on walkability. Fig. (8):

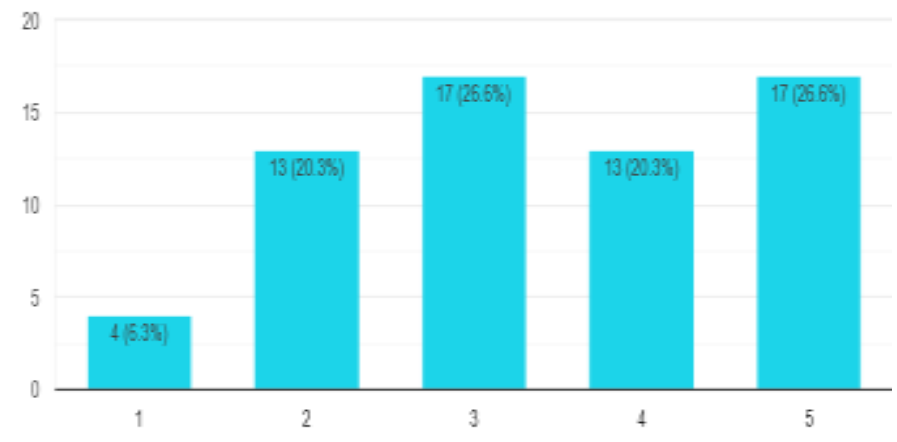

Fig. (8): Dependency on walkability for activities inside the neighborhood

\subsection{Evaluation of elements of PS in Al-Falah}

To explore the community's satisfaction regarding the design elements of PS, measuring accessibility, furniture, comfort and safety, green environment, a set of questions (Part3) was designed using Likert-type scaling of 5 grades scale to evaluate the elements of PS in Al-Falah. The results are shown in table (2). The results showed that people's satisfaction is average in general. Sidewalks, pedestrian safety, stability for elders and disabled respectively gained the highest satisfaction rate, while street signage, garbage, furniture were the least and trees and plants were the lowest stratifying elements among all.

\begin{tabular}{lccccccc}
\multicolumn{7}{c}{ Table 3. Evaluation of PS elements in Al Falah neighborhood } \\
\hline Sidewalks & $\mathbf{1}$ & $\mathbf{2}$ & $\mathbf{3}$ & $\mathbf{4}$ & $\mathbf{5}$ & Mean & Rank \\
\hline Pedestrian crossing & $10 \%$ & $10 \%$ & $22.9 \%$ & $22.9 \%$ & $34.3 \%$ & 3.6 & 1 \\
\hline Trees and plants & $13.4 \%$ & $11.9 \%$ & $26.9 \%$ & $23.9 \%$ & $23.9 \%$ & 3.3 & 4 \\
\hline Street's furniture & $34.5 \%$ & $15.5 \%$ & $22.4 \%$ & $19 \%$ & $8.6 \%$ & 2.5 & 8 \\
\hline Street's signage & $24.3 \%$ & $18.6 \%$ & $25.7 \%$ & $21.4 \%$ & $10 \%$ & 2.7 & 7 \\
\hline Garbage containers & $17.6 \%$ & $19.6 \%$ & $17.6 \%$ & $31.4 \%$ & $13.7 \%$ & 3.0 & 5 \\
\hline
\end{tabular}




\begin{tabular}{lccccccc}
\hline Pedestrian safety & $12.5 \%$ & $9.4 \%$ & $17.2 \%$ & $32.8 \%$ & $28.1 \%$ & 3.5 & 2 \\
\hline $\begin{array}{l}\text { suitability for elders and people } \\
\text { with special needs }\end{array}$ & $12.5 \%$ & $15.6 \%$ & $18.8 \%$ & $25 \%$ & $28.1 \%$ & 3.4 & 3 \\
\hline
\end{tabular}

Note: Survey respondents were asked, "On a scale from 1 to 5 , with 1 being 'not satisfied at all," and 5 being 'very satisfied.

\subsection{Evaluation of PS development impact on People's QoL}

To explore the impact of the PS development project in Al-Falah on the community's QoL, measuring the collective impact of the five dimensions, a set of questions (Part4) were designed using Likert-type scaling of 5 grades scale to evaluate the participant's opinion of the impact of each element of the project on their QoL. Based on the results are shown in table (4): people's evaluation is high in general.

Enhancing the QoL was the highest impact agreed on by the respondents. Improving safety, the visual image of the district encourages more social activities, and more walkability is the four-second top impacts, respectively. The effect of adding scooters was the least. Almost half of the sample (47\%) highly agreed to participate in the development project, reflecting their overall satisfaction with their gain from the project on their lifestyle.

Table 4. Evaluation of PS development impact on People's QoL

\begin{tabular}{|c|c|c|c|c|c|c|c|}
\hline & 1 & 2 & 3 & 4 & 5 & Mean & Rank \\
\hline $\begin{array}{l}\text { Wide Sidewalks encourages more } \\
\text { walkability }\end{array}$ & $5.7 \%$ & $7.1 \%$ & $15.7 \%$ & $21.4 \%$ & $50 \%$ & 4.02 & 5 \\
\hline Scooters encourage more outings & $9.8 \%$ & $4 \%$ & $23.5 \%$ & $15.7 \%$ & $47 \%$ & 3.86 & 6 \\
\hline $\begin{array}{l}\text { PS Development encourages more social } \\
\text { activities }\end{array}$ & $3 \%$ & $4.2 \%$ & $24.3 \%$ & $18.5 \%$ & $50 \%$ & 4.08 & 4 \\
\hline $\begin{array}{l}\text { PS Development enhances the visual } \\
\text { image }\end{array}$ & $0 \%$ & $7.8 \%$ & $19.6 \%$ & $23.5 \%$ & $49 \%$ & 4.14 & 3 \\
\hline PS Development enhances the safety & $4 \%$ & $0 \%$ & $17.6 \%$ & $33.4 \%$ & $45 \%$ & 4.16 & 2 \\
\hline $\begin{array}{l}\text { PS Development enhances QoL inside } \\
\text { the district }\end{array}$ & $4 \%$ & $4 \%$ & $9.8 \%$ & $35.3 \%$ & $47 \%$ & 4.18 & 1 \\
\hline $\begin{array}{l}\text { l'd like to participate in the PS } \\
\text { Development project }\end{array}$ & $11.8 \%$ & $2 \%$ & $21.6 \%$ & $17.6 \%$ & $47 \%$ & 3.86 & 6 \\
\hline
\end{tabular}

Note: Survey respondents were asked, on a scale from 1 to 5 , with 1 being 'highly disagree' and 5 beings 'highly agree.'

\subsection{Discussion}

According to the New Urban Agenda by UN-Habitat in 2020, "Urban Planning and design's instruments are created to expand, protect and promote the public realm and enhance the liveability of urban neighborhoods. Planning and design regulations should strive to promote a sense of security, comfort, and inclusivity in the built environment "(UN-Habitat 2020). However, this study investigated the alignment of the QoL program with the five dimensions of successful public spaces as stated by the UN-Habitat Public Spaces program to align with the new urban agenda. Although the framework of the "Humanization of Cities" initiative's objectives are well defined, the application of the initiative in the ground needs to follow the standard-based urban design to avoid short outcomes in many aspects, such as parking lots, trees, etc. streets furniture. The study found that people's sense of safety has increased with the application of the " upgrading PS project," which confirms the outcomes of the previous studies that more people walking creates more activities and opportunities for social interaction, which helps prevent loneliness and stimulate social cohesion. Results showed a high tendency for walkability that encourages considering walking and cycling affordable modes of mobility. Yet, providing a very wide sidewalk without considering the actual needed number of parking lots caused a problem that cars are parking over the sidewalks, which point to designing without adequate consideration of all needs. Providing safety design solutions, inclusive design for elders and people with difficulties, streets furniture, and good plantation are amongst the top-rated highly impact elements of PS in the neighborhood which aligned with the five dimensions of successful PS by Public Space program. Welling to participate in placemaking activities is a positive sign of people's appreciation of the role of PS to the QoL. There's a demand for a continuous pedestrian network along the district, adding sports courtyards and social clubs, planting more trees and plants.

\subsection{Conclusion\& Recommendations}

The overall aim of this research was to contribute to the discourse on contemporary urban QoL and PS qualities in residential neighborhoods. The research process involved an investigation of the QoL of a neighborhood in Saudi's capital, Riyadh. Conducting a structured survey to investigate the community evaluation and answer the study objectives through a multi-layered methodology and framework. This has resulted in a conclusion that captures the relationship between urban design elements and how they work together to contribute to the QoL. The paper contributes to urban design research, decision making, and practice in two dimensions: (1) guiding researchers and practitioners through academic research and evidence-based neighborhood design recommendations and (2) to policymakers and city urbanists through the development of research-informed urban policies and enhancing the application of the "Humanization of Neighbourhoods Initiative" when applying into other districts in Riyadh through the resolution of urban issues in this case-study neighborhood and eventually to the whole city.

Whereas driving in a private car and even public transport can be too expensive for some low-income groups in cities. While encouraging active mobility and reducing motorized vehicles have a considerable positive impact on pollution, reducing travel times in 
neighborhoods and restricting parking help improve pedestrian crossings and provide better connections to the gardens.

The study showed that the Riyadh Municipality succeeded in achieving many of the QoL Program goals related to the neighborhood's environment by upgrading public spaces and promoting residents' daily activities through conducting the "Upgrading PS in Neighbourhoods" project. Yet, the survey results explained how this project could be enhanced by considering the community's actual needs. It's also clear how the development of PS contributes enormously to encouraging physical activities for neighborhoods' residents.

Considering the need for walkability through transport planning (reduced traffic speed; providing more streets furniture) can encourage more pedestrians and impact traffic safety. Improved streets network designs that stimulate active mobility are one way of addressing inequality. Understanding the correlation between streets design as the main PS and QoL in the neighborhoods is one of the good outcomes that could be built on for future similar projects. Since the best undertaking involvement is a partnership between the dynamism of the private sector, the stewardship of public entities, and the energetic forces of citizens (Mostafa, L. 2017), therefore It's highly recommended to study practical engaging of local communities in placemaking projects on the neighborhood's level. Moreover, according to (Al-surf, Mostafa, 2017) that needs to activate the role of civil organizations that encourage volunteering, and this will fuel the development of non-selfish involvement of the young generations who might be unemployed and getting them volunteering can open employment doors and also help get necessary work done.

It's recommended for Riyadh municipality to improve accessibility for women and girls and persons with disability by employing design sensitive solutions, increasing livelihood opportunities in PS for youth, adding urban amenities to increase comfort in PS like solar lighting, waste bins, and others, and benefitting from the urban landscape to create an attraction inside the neighbouhood.

Finally, PS's current development project is a unique opportunity to interpret and educate natural values and the community's history and culture, including the physical and social activities; it also presents an excellent opportunity for a best practice if the community feedback was put into concern. It's recommended for a similar project to conduct a pilot comprehensive small-scale placemaking project in each neighborhood to showcase the intended development and simulate community participation amongst the residents.

\section{Acknowledgments}

(The author extends the appreciation to the Deanship of Postgraduate and Scientific Research at Dar Al Uloom University for funding this work.)

\section{Paper Contribution to Related Field of Study}

The research highlighted the critical features residents need inequitable walking access to everyday life, public services, social infrastructure, green spaces. It increased social cohesion by covering daily functional needs, enabling incidental encounters between residents, improving social relations. Moreover, this also implies local decision-making empowerment and community participation inclusivity.

\section{References}

Arup, (2016). Cities alive: towards a walking world. London, Retrieved on $4^{\text {th }}$ November 2021 from: (http://publications.arup.com/publications/c/cities_alive_towards_a_walking_world

Breda. Joao, (2018). Transforming public spaces to promote physical activity- a key contributor to achieving the Sustainable Development Goals in Europe, The European Journal of Public Health 28(suppl_4), DOI: 10.1093/eurpub/cky212.599.

Goodyear, Sarah, (2013). A new way of understanding "Eyes on the Street." CityLab; Retrieved on 19th March 2017 from: (https://www.citylab.com/equity/2013/07/newway-understanding-eyesstreet/6276.

Hagen, B., Nassar, C., \& Pijawka, D. (2017). The Social Dimension of Sustainable Neighborhood Design: Comparing Two Neighborhoods in Freiburg, Germany. Urban Planning, 2(4), 64-80. https://doi.org/10.17645/up.v2i4.1035

Hamiduddin, I. (2015). Social sustainability, residential design, and demographic balance: Neighbourhood planning strategies in Freiburg, Germany. Town Planning Review, 86(1), 29-52. doi:10.3828/tpr.2015.3

Kelly P, Kahlmeier S, Götschi T, Orsini N, Richards J, Roberts N, et al.. (2014). Systematic review and meta-analysis of reduction in all-cause mortality from walking and cycling and shape of a dose-response relationship. Int J Behav Nutr Phys Act. 2014;11:132. doi:10.1186/s12966-014-0132-x.

Lee IM, Shiroma EJ, Lobelo F, Puska P, Blair SN, Katzmarzyk PT.(2012). Effect of physical inactivity on major non-communicable diseases worldwide: an analysis of disease burden and life expectancy. Lancet 380 (9838):219-29. doi:10.1016/S0140-6736(12)61031-9.

Lawlor E., (2018). The pedestrian pound: the business case for better streets and places. Living Streets; Retrieved on $4^{\text {th }}$ November 2021, from: (https://www.livingstreets.org.uk/media/1391/pedestrianpound_fullreport_web.pdf

Lobna A. Mostafa,( 2017). Urban and Social Impacts of Waterfronts Development, Case Study: Jeddah Corniche, Procedia Environmental Sciences, Volume 37, Pages 205-221, ISSN 1878-0296, https://doi.org/10.1016/j.proenv.2017.03.035. (https://www.sciencedirect.com/science/article/pii/S187802961730035X)

MOH. (2020). Humanizing Neighborhoods Initiative.

Machline E, Pearlmutter D, Schwartz M, Pech P. (2020). Green neighborhoods and Eco gentrification: a tale of two countries. Springer Nature. https://doi.org/10.1007/978- 
Mohammed S. Al Surf, Lobna A. Mostafa,( 2017). Will the Saudi's 2030 Vision Raise the Public Awareness of Sustainable Practices? Procedia Environmental Sciences, Volume 37, P 514-527, ISSN 1878-0296, https://doi.org/10.1016/j.proenv.2017.03.026. (https://www.sciencedirect.com/science/article/pii/S1878029617300269).

Murphy, K. (2012). The social pillar of sustainable development: A literature review and framework for policy analysis. Sustainability: Science, Practice \& Policy, 8 (1), $15-29$.

Quality of living city ranking, (2019). retrieved in October 2020: https://mobilityexchange.mercer.com/Insights/quality-of-living-rankings

Rey. Emmanuel, Martine. Laprise, and Lufkin, Sophie. (2022). Sustainability Issues at the Neighbourhood Scale, Neighbourhoods in Transition (5) 77-93. DOI: 10.1007/978-3-030-82208-8_5, https://www.researchgate.net/publication/354853001_Sustainability_Issues_at_the_Neighbourhood_Scale

Riyadh Urban Design Guidelines. (2019). retrieved on October 2021: https://www.rcrc.gov.sa downloads publication

Sallis JF, Cerin E, Conway TL, Adams MA, Frank LD, Pratt M, et al.(2016). Physical activity in relation to urban environments in 14 cities worldwide: a cross-sectional study. Lancet 2016;387(10034):2207-17. doi:10.1016/S0140-6736(15)01284-2.

Stren, R., \& Polèse, M. (2000). Understanding the new socio-cultural dynamics of cities: Comparative urban policy in a global context. In M. Polèse \& R. Stren (Eds.), The social sustainability of cities: Diversity and change management (pp. 3-38). Toronto: University of Toronto Press.

Tanguy A, Breton C, Blanchet P, Amor B. (2020). Characterising the development trends driving sustainable neighborhoods. Build Cities 1:164-181. https://doi.org/10.5334/bc.22

The WHOQOL Group, The World Health Organization quality of life assessment (WHOQOL): Position paper from the World Health Organization, 1995, https://doi.org/10.1016/0277-9536(95)00112-K Retrieved on $4^{\text {th }}$ November 2021

UN-Habitat. (2020). New Urban Agenda, United Nations Human Settlements Programme (UN-Habitat) 2020, P79-80.

UN-Habitat. (2020). Global Public Space Programme Annual Report, United Nations Human Settlements Programme (UN-Habitat) 2020, P20-23

UN-Habitat. (2020). "The Value of Sustainable Urbanization" World Cities Report, United Nations Human Settlements Programme (UN-Habitat) 2020, p117-119

WHO, What is a healthy city? (2019). Copenhagen: WHO Regional Office for Europe, Retrieved on 4th November 2021, https://www.euro.who.int/en/healthtopics/environment-and-health/urban-health/who-european-healthy-cities-network/what-is-a-healthy-city

WHO, Making walking safe: a brief overview of pedestrian safety around the world. (2017). Retrieved on $4^{\text {th }}$ November 2021 from: (http://who.int/violence_injury_prevention/publications/road_traffic/make_walking_safe.pdf

WHO, Towards more physical activity in cities, Transforming public spaces to promote physical activity. (2017). retrieved on $4^{\text {th }}$ November 2021 from: www.euro.who.int > assets > pdf_file > 2017_WHO_Report_FINAL_WEB

Vision 2030 VRP Quality of Life Program. (2016). KSA, retrieved from: https://www.vision2030.gov.sa/v2030/vrps/qol/, on May 2019. 